\title{
Packed-column SFC in the pharmaceutical industry: cGMP aspects
}

\author{
K. Anton and C. Siffrin \\ Chemical \& Analytical Development, Novartis Pharma AG, 4002 Basel, Switzerland
}

\begin{abstract}
General aspects of drug development are discussed in the context of current Good Manufacturing Practice (cGMP) specified by various administrations. The potential of packedcolumn SFC (pSFC) instrumentation in the pharmaceutical industry is demonstrated along with different qualification parameters influencing chromatographic results, methods for their determination, and specifications defined in light of the $\mathrm{ICH}$ (International Conference on Harmonisation) Guideline for industry. Standard Operation Procedures (SOPs) are described for measuring flow rate, pressure, temperature, linearity and precision, sample carry-over, noise and drift, composition gradient, and wavelength accuracy of the pSFC instrumentation. The strong requirements for impurity and/or assay methods lead to a relative high effort of validation: beside selectivity, linearity and precision must be demonstrated over a wide range of concentrations for several repeated injections; limit of detection (LOD) and limit of quantitation (LOQ) must be in compliance with the specifications for impurity methods. A system suitability test (SST), filed together with the testing instructions of the drug, ensures that the PSFC instrumentation can be used for the analysis. Finally, method transfer between different systems and further instrumental improvements are discussed.
\end{abstract}

Keywords: pSFC, cGHP, SOPs, SST, ICH, drug, substances analysis, validation

\section{General Aspects}

\section{Drug development process}

Drug development in the pharmaceutical industry is a longterm process starting with the hand-over of a drug-substance candidate from research and ending with the appearance of a new drug on the market [1]. Several stages have to be passed through: choice of the drug-substance candidate after the preclinical screening phase, application of the investigational new drug (IND), formulation of the drug product, and subsequent new drug application (NDA) needed for marketing approval of the drug as a medicine.

\section{Types of analysis}

The quality of drug substance and drug product has to be tested according to the future use of the produced batch (technical, toxicological or clinical use). Therefore, intensive analysis has to be done to set specifications, which can later be used for quality control during full-scale production. The different types of analysis during such a development process are summarized in table I. Analytical guidelines for this process were fixed within different Expert Working Groups of the International Conference on Harmonization (ICH) of Technical Requirements for Registration of Pharmaceuticals for Human Use [2-6].

The impurity check of the drug substance or drug product is currently the most important analysis, giving essentially the fingerprint of the chemical synthesis and of the stability studies. Impurity tests include "process contaminants" (inorganics, reagents, solvents) and so-called "related substances" (homologues, analogues, by-products from synthesis or degradates) which are chemically related to the drug and arise from the manufacturing process, or are formed during the manufacturing process [7].

Today, the method of choice for assay and impurity analysis during the development and production of drugs is reversed-phase HPLC (RP-HPLC). The results are given in percentage peak-area, otherwise in percentage compared to a defined standard.

\section{Current GMP for analytics}

Pharmaceutical companies, that produce drugs for toxicological and clinical trials, and later for the use on the market, must work according to the ICH Guidelines for Industry which include the current Good Manufacturing Practice (cGMP). The goal of cGMP is to encourage designing quality into a product from the beginning of the development and not just at the very end in the marketed product. The confirmation of the quality of a product is the result of the combination of the amount of validation data for the process, the amount of in-process testing, and the amount of finishedproduct testing [8].

To work according to cGMP, most companies involved in the development of pharmaceuticals build up a Quality Assurance (QA) unit independently from the analytics. All procedures are written down in Standard Operating Procedures (SOPs) which have the status of "laws" within the company. In addition, all hardware and software of 
Table I. Different types of assay and impurity analysis during drug substance and drug product development and for quality control of the marketed medicine.

\begin{tabular}{|c|c|c|}
\hline & Drug substance & Drug product \\
\hline Research & Assay & Not yet defined \\
\hline Development & $\begin{array}{l}\text { Release/re-test of } \\
\quad \text { - raw material(s) } \\
\quad \text { - intermediate(s) } \\
\text { - drug substance } \\
\text { Stability as } \\
\quad \text { - forced decomposition } \\
\quad \text { - stress condition } \\
\text { - normal /accelerated conditions } \\
\text { Impurity profile(s) of different batch(es) }\end{array}$ & $\begin{array}{l}\text { Release/re-test of } \\
\quad \text { - excipient(s) } \\
\quad \text { - preservative(s) } \\
\text { - drug product } \\
\text { Stability as } \\
\quad \text { - forced decomposition } \\
\text { - stress condition } \\
\text { - normal/accelerated conditions } \\
\text { Impurity profile(s) of different batch(es) }\end{array}$ \\
\hline Market product & $\begin{array}{l}\text { Release of } \\
\quad \text { - raw material(s) } \\
\quad \text { - intermediate(s) } \\
\text { - drug substance } \\
\text { Stability (follow up) }\end{array}$ & $\begin{array}{l}\text { Release of } \\
\quad \text { - excipient(s) preservative(s) } \\
\quad \text { - content uniformity } \\
\text { - drug product } \\
\text { Stability (follow up) }\end{array}$ \\
\hline
\end{tabular}

analytical instruments in laboratory, pilot, and production must undergo the qualification procedures: installation qualification (IQ), operational qualification (OQ), and performance qualification (PQ) [9]. The complexity of the qualification test depends on the complexity of the instrument. While IQ and OQ are done by the company delivering the instrumentation during the installation, the PQ is mainly done periodically according to the appropriate SOP of the pharmaceutical company. If the performance specifications are not met, the instrument should be taken out of use (e.g. by labeling "non-GMP") and repaired.

Before a sequence of an analytical method is started, the performance of the separation system must be confirmed. This is done by a method-specific system-suitability test (SST), which can be written down in the testing procedure and must be fulfilled before or during the analysis sequence of the sample. For the validation of quantitative impurity methods used for the registration process, the following parameters must be validated according the ICH Guidelines for industry $[2,3]$ and met specifications: precision (repeatability, intermediate precision, and reproducibility), specificity (peak purity), linearity, limit of detection (LOD), limit of quantitation (LOQ), accuracy (recovery), and stability of the sample solution.

The traceability of all data generated during drug development and production must be guaranteed in the documentation. The history of instruments, columns, reagents and weight-ins must be documented (e.g. in log-books). The methods should be rugged enough to be used in laboratories other than those where the method was developed, e.g. labs of the US Food and Drug Administration (FDA).

Only the high standard and good reproducibility of analytical methods in compliance with cGMP can guarantee a correct comparison of impurity profiles of drug substance batches, which are produced at different development stages and used for different toxicological and clinical studies. In batches prepared for clinical studies, impurity amounts that deviate from those found in the batches used for toxicology should absolutely be avoided.

\section{Packed-column SFC as a separation technique orthogonal to RP-HPLC}

Orthogonal separation techniques are essential in the registration process to show that the mainly-used RP-HPLC gives reliable results. Packed-column SFC (pSFC) is a normalphase (NP) separation technique, the elution order is different compared to RP-HPLC. Compounds not eluting from an RP-HPLC column can elute from a NP column used in pSFC. First quantitative results of drugs with pSFC were already published in the early nineties $[10,11]$, commercial instruments of pSFC were available since 1992 [12-15] and the technique itself is already accepted or in discussion within the authorities [16]. Therefore, besides other techniques, such as NP-HPLC, capillary electrophoresis (CE) and gas chromatography (GC), pSFC should also be fore- 
seen as an orthogonal separation technique to RP-HPLC to meet the requirements of a safe drug for the market.

The physical properties of the highly compressible fluid used as a mobile phase in pSFC (carbon dioxide with some percentage of modifier, mainly methanol) lead to faster mass transfer compared to liquids. The resulting faster analytics already save time during method development, because the column is equilibrated in less time when compared with RPHPLC. In other respects, these physical properties of compressible fluids result in a restriction of the injection volume and in an increase of the noise level of the ultraviolet (UV) detector. Therefore, the limit of quantitation (LOQ) used as a SST for impurity methods (e.g. reporting level of $0.05 \%$ of drug substance) can only be reached sometimes for goodsolubility samples. However, the different order of elution, together with the very short elution times, can lead to rather similar LOQs for pSFC and RP-HPLC.

\section{Experimentals}

The following two pSFC systems were used and have been modified as described to maximize the performance for quantitative analysis under cGMP. Additionally, this section presents the devices used to measure pressure, flow rates and temperature.

\section{pSFC system Series SF3 modular from Gilson S.A. (Villiers-le-Bel, France): system 1}

This system consists of a single-piston pump for carbon dioxide (308/5SC), and single-piston pump to deliver modifier (306/5SC), pulse dampener (inside the 821 module), two dynamic mixers ( $811 \mathrm{C}$ with $1.5 \mathrm{ml}$ chamber each) (an additional one compared with the basic system), autosampler (231 XL), column oven (831), heat exchanger (inside the 821 module), UV detector (Linear UVIS200, $2 \mathrm{~mm}$ light-path) and a two-stage variable back-pressure regulator (821) modified with extra heating $\left(80^{\circ} \mathrm{C}\right)$ of the Nupro valve (outside of the column oven) for final decompression from $9 \mathrm{MPa}$ to atmospheric pressure.

\section{pSFC system from Berger Instruments, Inc. (Newark, DE, USA): system 2}

This system consists of a pump module, with carbon dioxide and modifier pump (one-and-a-half-head pumps, pulse dampener, static mixer), autosampler, column oven, UV detector (HP1100 DAD, 6 mm light-path) and a single-stage variable backpressure regulator (at $80{ }^{\circ} \mathrm{C}$ ).

\section{pSFC system Series SF3 modular from Gilson S.A. (Villiers-le-Bel, France): system 3}

As system 1 but without the extra heating device for the Nupro valve for final decompression from $9 \mathrm{MPa}$ to atmospheric pressure.

\section{Certified pressure transducer}

Pressure transducer ED513 \& ZED501 from Haenni Instruments AG (Jegenstorf, Switzerland). Certified calibration: 0-40 MPa.

\section{Flowmeter}

Coriolis flowmeter PROMASS63 from Endress+Hauser AG (Reinach, Switzerland). Maximum pressure: $30 \mathrm{MPa}$.

\section{Certified thermometer}

Digital thermometer P510 from Bakrona AG (Basel, Switzerland).

\section{Reagents and chemicals}

In all pSFC experiments, SFC-grade carbon dioxide was used from Carba Gas (Basel, Switzerland). The modifiers, methanol and ethanol, were both LiChrosolv gradient-grade from Merck KGaA (Darmstadt, Germany). For the linearity test, methylparaben (Novartis Pharma working standard 0054834) was dissolved in methanol LiChrosolv gradientgrade from Merck. For the composition-gradient test, a solution of toluene, LiChrosolv for chromatography from Merck, was prepared with a concentration of about $400 \mathrm{ppm}$ in methanol LiChrosolv gradient-grade from Merck. The drug substance in development at Novartis Pharma AG (Basel, Switzerland) defined in this publication as Novartis Pharma Drug Substance in Development (NPDSD) was dissolved in tetrahydrofuran for HPLC from Fluka Chemie AG (Buchs, Switzerland).

\section{Chromatographic columns}

Packed columns from Bischoff Analysentechnik (Leonberg, Germany) were used, based on the packing material Prontosil 120, $5 \mu \mathrm{m}$, with dimensions $250 \times 3.0 \mathrm{~mm}$ and $250 \times 2.0 \mathrm{~mm}$. For method development, columns with modified silica and bare silica were evaluated. The final method used bare silica columns (part numbers 2503F000PS050 and 2502F000PS050).

\section{pSFC instrumentation}

In 1992, commercial pSFC instruments based on reciprocating pumps, packed columns, mixed mobile phases, UVabsorbance detection, and variable computer-driven restriction devices were commercially available [12-15]. With this instrumental design, independent and full control over flow rate, composition, temperature, and pressure is possible.

As already mentioned above, the different qualification procedures (IQ, OQ and PQ) are needed to comply with the cGMP requirements. The correct installation of the system (IQ) at the customer's lab must be followed by proving the functionality of all instrumental parts according to the specified performance given by the manufacturer (OQ). At least 
the repeatability and the sample carry-over have to be determined by a short sequence of injections of a standard sample mixture, separated on a standard column, and they must meet the manufacturer's specifications.

After the IQ and OQ, the user of the instrument has to prove periodically the performance of the system according to a SOP written by company experts and proved by the QA in place. This SOP, which has to be applied, describes a system test and specifications for all important parameters: e.g. flow rate (carbon dioxide and modifier), pressure at the column inlet and at the column outlet, temperature (oven), LOD, LOQ, linearity (whole concentration range in question), repeatability, detector noise level, composition gradient and accuracy of detector wavelength. As an example, table II lists the parameters, their proposed specifications and the appropriate test methods. To evaluate the proposed specifications, the parameters were evaluated with two pSFC systems delivered by different instrumental companies. These systems are in use in a cGMP laboratory for analytical development at Novartis Pharma AG and are not generally representative for these types of instrument.

\section{Flow rate}

The flow rate of the mobile phase has an influence on both retention time and peak area of an eluted compound. The high compressibility of the fluid in pSFC leads to a correlation between flow rate and elution strength. Increased flow rate leads to increased back-pressure and therefore to a steeper density gradient along the column, which reduces the retention time of an eluted compound. In HPLC, the flow rate of the pump is evaluated in the system performance test (PQ) by collecting a defined volume delivered by the pump and measuring the time. In pSFC this can only be applied for the modifier pump. The determination of the flow rate of a highly compressible fluid is more difficult. Three possible ways can be discussed:

(1) The volume of the expanded carbon dioxide can be collected in a pneumatic bath. With the known density of the fluid in the system, the flow rate can be estimated (e.g. the flow of $1 \mathrm{ml} / \mathrm{min}$ liquid carbon dioxide at $6 \mathrm{MPa}$ and $7^{\circ} \mathrm{C}$, density $0.904 \mathrm{mg} / \mathrm{ml}$ corresponds to 0.5 liter gas [12]). Some flow rate evaluations are demonstrated in figure 1. At the same nominal conditions the different systems show different flow rates: system 1, before maintenance, delivers much less carbon dioxide compared to system 2 or system 3 . The flow of fluid/liquid carbon dioxide can be estimated with the density: the flow rate of system 1 is only about $2.5 \mathrm{ml} / \mathrm{min}$ instead of the theoretical $3.0 \mathrm{ml} / \mathrm{min}$ (system 2: $3.2 \mathrm{ml} / \mathrm{min}$, system 3: $3.0 \mathrm{ml} / \mathrm{min}$ ). After maintenance (changing seals and check valves), system 1 is pumping about $3.2 \mathrm{ml} / \mathrm{min}$, which is within the proposed specified range (Tab. II).

(2) The loss of weight of the carbon dioxide tank during pumping can be recorded by a certified balance over a time period of about 3 hours. With the density, the average flow rate during this time can be calculated.

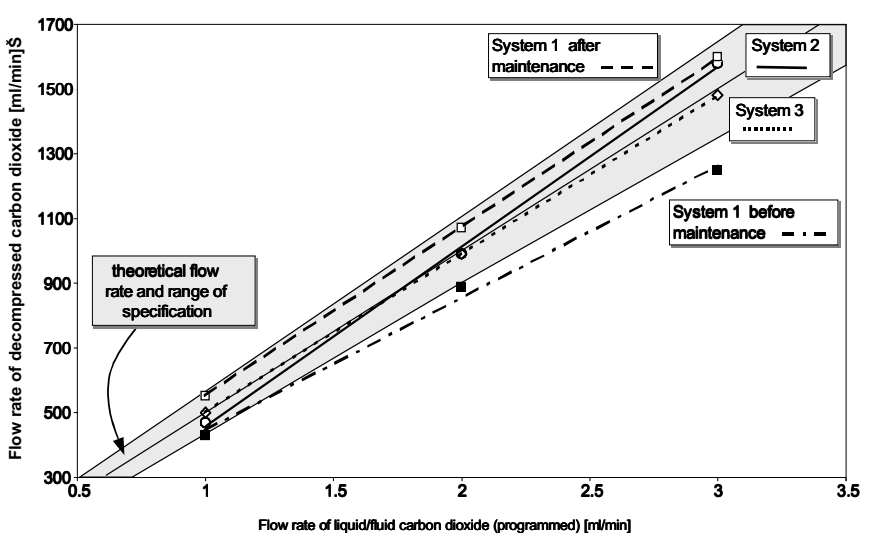

Figure 1. Determination of the gas flow-rate of decompressed carbon dioxide of two pSFC systems using a pneumatic bath. E.g. $1500 \mathrm{ml} / \mathrm{min}$ decompressed gas corresponds to about 3.0 $\mathrm{ml} / \mathrm{min}$ liquid carbon dioxide. pSFC conditions: outlet pressure: $11 \mathrm{MPa}$; temperature: $40{ }^{\circ} \mathrm{C}$; modifier: $0 \%$; column: Prontosil$120 \mathrm{Si}, 5 \mu \mathrm{m}, 250 \times 3.0 \mathrm{~mm}$.

(3) The flow rate of the fluid is measured directly in the system. This can be done using a certified flowmeter which determines the mass flow rate in an oscillating tube by the shift of phase of the resonance frequency created by Coriolis forces. The resonance frequency gives the actual density of the medium inside the tube of known volume. With this instrument, it is possible to calculate the volume flow rate from the measured values of density and mass flow rate. The results of the direct determination of the flow rate of system 1 , system 2 and additional system 3 can be seen in figure 2. As already shown in figure 1 , system 1 delivers (before maintenance) less flow compared to system 2 at the same nominal conditions. With this flow measurement

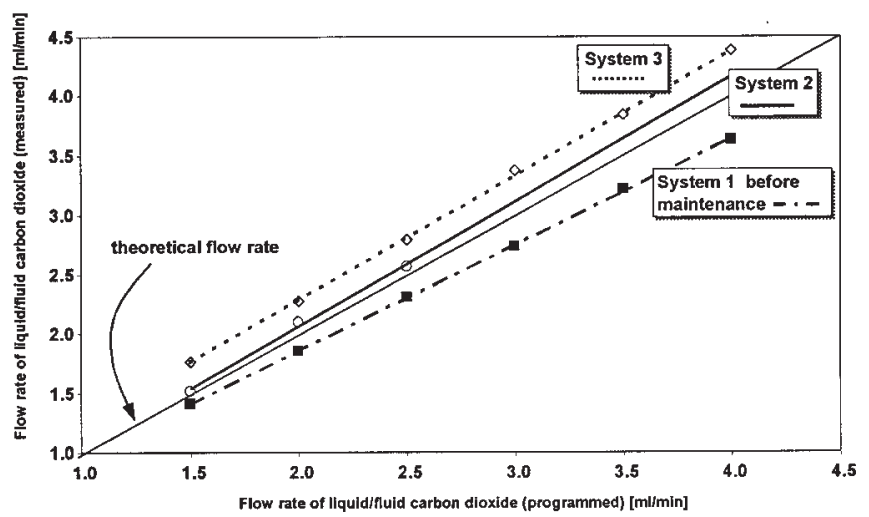

Figure 2. Direct determination of the liquid/fluid flow rate of carbon dioxide in the system using the Promass63 flowmeter. pSFC conditions, see figure 1 . 
Table II. Proposal for test parameters and their specifications in a SOP to be used for pSFC instruments.

Test parameter Test method Specifications

Flow rate Carbon dioxide:

(carbon dioxide, (1) Certified flowmeter for liquid/fluid carbon dioxide $\quad$ At $1.5 \mathrm{ml} / \mathrm{min}: \pm 0.15 \mathrm{ml} / \mathrm{min}^{1}$

modifier) (2) Certified gas flowmeter for gaseous decompressed carbon dioxide At $3.0 \mathrm{ml} / \mathrm{min}: \pm 0.3 \mathrm{ml} / \mathrm{min}^{1}$

(3) Collecting a defined volume of the decompressed gas combined At $4.5 \mathrm{ml} / \mathrm{min}: \pm 0.45 \mathrm{ml} / \mathrm{min}^{1}$

with time measurement

Modifier:

Collecting a defined volume of modifier in a flask combined $\quad 0.05 \mathrm{ml} / \mathrm{min}: \pm 0.01 \mathrm{ml} / \mathrm{min}$

with time measurement $\quad 0.5 \mathrm{ml} / \mathrm{min}: \pm 0.05 \mathrm{ml} / \mathrm{min}$

$\begin{array}{lll}\begin{array}{ll}\text { Pressure } \\ \text { (inlet, outlet) }\end{array} & \text { Certified pressure transducer } & \\ & \text { Inlet pressure: between pump and column } & 10-20 \mathrm{MPa}: \pm 1 \mathrm{MPa} \\ & \text { Outlet pressure: between detector and back-pressure regulator } & 20-30 \mathrm{MPa}: \pm 2 \mathrm{MPa} \\ & & 30-40 \mathrm{MPa}: \pm 3 \mathrm{MPa}\end{array}$

Temperature Certified thermometer At 50, 100 and $130{ }^{\circ} \mathrm{C}: \pm 3^{\circ} \mathrm{C}$

(column oven)

Linearity, $\quad$ Sequence of duplicated injections of a dilution series $100-0.05 \%$

Repeatability of methylparaben in methanol ${ }^{2}$

Peak for $0.05 \%$ solution

must be visible

Linearity $(0.1-100 \%)$ :

correlation coefficient $r \geq 0.998$

Repeatability: residual standard

deviation relative to

$100 \%$ RSD $\leq 1.5 \%$

Sample carry-over: $\leq 0.05 \%$

Sample carry-over Injection of pure solvent after injection of a $100 \%$ solution of methylparaben in methanol

Noise and drift Recording the detector signal at $254 \mathrm{~nm}$ during $(5 \mathrm{~Hz}$ sampling rate, rise time $1.0 \mathrm{~s}) 30 \mathrm{~min}$ at the following conditions (corresponding to

Noise level: $\leq 0.5 \mathrm{mAU}$ the test conditions for linearity) $)^{2}$

Drift: $\leq 2 \mathrm{mAU} / \mathrm{h}$ the test conditions for linearity ${ }^{2}$

\section{Composition Recording the detector signal during gradient at $260 \mathrm{~nm}$,} gradient four repeated profiles ${ }^{3}$

Wavelength accuracy

\section{Filling the detector cell with a solution of pyrene in methanol;} recording the spectrum
At $<10 \%$ modifier: $\pm 0.5 \%$

At $>10 \%$ modifier: $\pm 1.0 \%$

\footnotetext{
${ }^{1}$ In the case of system 1 the programmed flow is not identical with the actual flow rate. There is a factor of about 0.8 between actual and programmed flow, e.g. when $3.0 \mathrm{ml} / \mathrm{min}$ is programmed only about $2.4 \mathrm{ml} / \mathrm{min}$ are delivered (see text).

${ }^{2}$ Using alternatively two testing conditions: temperature (oven): $40{ }^{\circ} \mathrm{C}$ and/or $100{ }^{\circ} \mathrm{C}$; Total flow: $2.0 \mathrm{ml} / \mathrm{min}$; modifier (methanol): 3 and/or $6 \%$; Pressure (outlet): $11 \mathrm{MPa}$; column: e.g. Prontosil-120 Si, $5 \mu \mathrm{m}, 250 \times 2.0 \mathrm{~mm}$.

${ }^{3}$ Using the following conditions: temperature (oven): $40{ }^{\circ} \mathrm{C}$; total flow: $2.0 \mathrm{ml} / \mathrm{min}$; modifier (methanol + toluene): gradient program see figure 4; pressure (outlet): $20 \mathrm{MPa}$.
}

set-up, system 3 shows a higher flow rate compared to system 2, contrary to the results of the flow measurement of decompressed gas in figure 1 . However, both measurements were carried out at different time.
The differences in flow rate can be caused by the difference between the models of different manufacturers. Also the daily performance of the system is given by the pump seals, check valves and accurate cooling of the carbon 
dioxide pump-head. As discussed in (1), it was found that, for system 1, the pump seals were worn off and the check valves not functioning properly. Therefore it is extremely important to determine the flow rate of the pSFC system, especially when methods are adapted from one system to another, e.g. system 2 to system 3 or backwards. However, both systems (from different manufacturers) met the specifications proposed in table II, while system 1 had to be serviced to fulfill also these requirements (Fig. 1).

\section{Pressure}

The elution strength in pSFC is directly influenced by the density of the fluid in the system. The higher the pressure, the higher the density. The pressure drop along the chromatographic column created by a defined flow rate leads to a density gradient. In pSFC, the system outlet pressure, after the column, can be set to a fix value by the programmable back-pressure regulation system. The system inlet pressure, before the column, depends on the flow rate and the flow resistance of the complete system (including column resistance). In most pSFC systems, the inlet and outlet pressure can be displayed. To verify the accuracy of these displayed pressure values and their possible change within time, and also for the comparison of different instruments, the pressure should be measured with a certified pressure transducer. The proposed specifications are set in table II.

\section{Temperature}

The accuracy of the temperature in the column oven is determined using a certified thermometer. The measuring point should be close to the column. The values can be taken over a 30-min period at three different temperatures (e.g. 50, 100 and $130{ }^{\circ} \mathrm{C}$ ). These values should be compared to the values displayed by the system. The proposed specifications are set in table II.

\section{Linearity, repeatability and sample carry-over}

To determine the linearity, repeatability and sample carryover, a series of solutions $(100,75,50,25,10,5,1$ and $0.05 \%)$ of methylparaben in methanol are injected. The concentrations are in the range of $0.9 \mathrm{mg} / \mathrm{ml}(100 \%)$ to 0.45 $\mu \mathrm{g} / \mathrm{ml}(0.05 \%)$. The results and the pSFC conditions are seen in table III. The requirements on linearity, repeatability and sample carry-over are fulfilled according to the proposed specifications set in table II.

\section{Noise and drift}

To determine the related substances, the level of these compounds should be quantified down to a $0.05 \%$ dilution of the drug substance solution (100\%). To quantify such a peak, the signal-to-noise ratio $(\mathrm{S} / \mathrm{N})$ must be 10 as a minimum. So, the noise level has to be lower than $0.005 \%$ of the signal created by the $100 \%$ solution. The linear range of modern DADs is specified up to $1000 \mathrm{mAU}$. In this case, the noise level must be less than $0.05 \mathrm{mAU}$ to quantify $0.05 \%$ of the related substances beside the $100 \%$ active drug substance. For instance, the Hewlett-Packard 1100 DAD is thus specified concerning the ASTM test: linear range $2 \mathrm{AU}$, noise level $1 \times 10^{-5} \mathrm{AU}$ at $254 \mathrm{~nm}$ [17].

Compared to HPLC, the UV-detector noise level is increased in pSFC. A very important effect on the noise level is caused by a temperature difference between the inner wall of the detector cell and the hot fluid from the oven passing through the detector cell. The flaws, caused by an inhomogeneous refractive index as a result of density differences, increase the noise level. With system 2, an excessive noise amplitude of more than $5 \mathrm{mAU}$ can be observed at 70 and $80{ }^{\circ} \mathrm{C}$ oven temperatures because of a missing heat exchanger. The noise level is minimum at an oven temperature of $40{ }^{\circ} \mathrm{C}$ (Fig. 3) compared to 35 and $45{ }^{\circ} \mathrm{C}$. At $40{ }^{\circ} \mathrm{C}$, the short-term noise level ( 2 minutes) is about $0.05 \mathrm{mAU}$. With this noise amplitude, it is in principle possible to reach the LOQ for a $0.05 \%$ solution as discussed above. At $45{ }^{\circ} \mathrm{C}$, the noise is about $0.22 \mathrm{mAU}$; and at $35^{\circ} \mathrm{C}$, it is $0.17 \mathrm{mAU}$. The missing heat exchanger leads to the fact that, for system 2, the proposed specifications (Tab. II) are only met at lower temperatures. This drastically restricts the use of temperature to optimize separations.

Investigations of these temperature effects conclude that, to reach a minimum noise amplitude, the fluid entering the detector cell must be at the same temperature as the detector cell itself. One practical solution can be to use an additional capillary $(300 \times 0.12 \mathrm{~mm}$, stainless steel $)$ as a transfer line between oven and detector for heating/cooling with

Table III. Specifications and results on linearity, repeatability and sample carry-over.

\begin{tabular}{lll}
\hline Test parameter & Specification & Result \\
\hline Linearity & Correlation coefficient $r \geq 0.998$ & 0.99987 \\
Repeatability & Residual standard deviation $\leq 1.5 \%$ & $0.61 \%$ \\
Relative y-intercept & $\leq 1.5 \%$ & $0.23 \%$ \\
Sample carry-over & $\leq 0.05 \%$ & $\leq 0.05 \%$ \\
\hline
\end{tabular}

pSFC conditions. Flow rate: $3.0 \mathrm{ml} / \mathrm{min}$; outlet pressure: $11 \mathrm{MPa}$; temperature: $40{ }^{\circ} \mathrm{C}$; modifier: $6 \%$ methanol; column: Prontosil-120 Si, $5 \mu \mathrm{m}, 250 \times 3.0 \mathrm{~mm}$; detection: UV, $254 \mathrm{~nm}$; injection: $5 \mu \mathrm{l}$. 


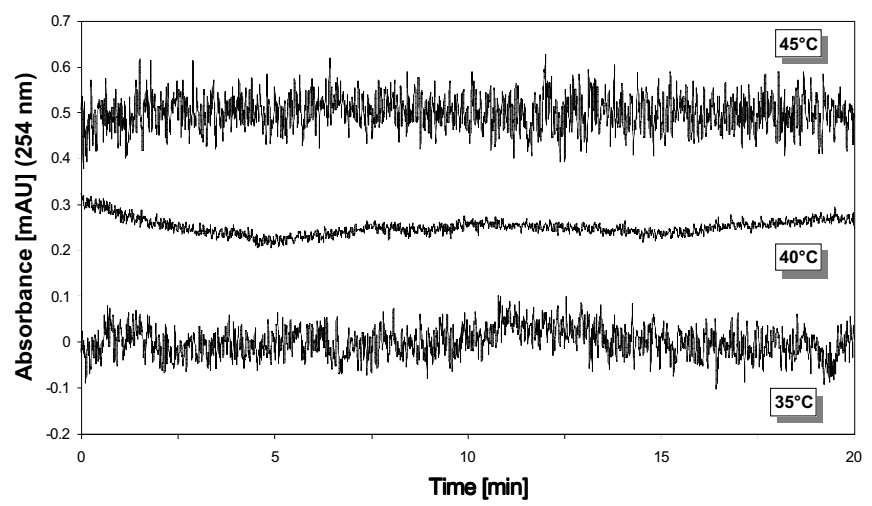

Figure 3. Influence of oven temperature on noise level of the DAD of system 2 during the following pSFC conditions: flow: $3.0 \mathrm{ml} / \mathrm{min}$; outlet pressure: $11 \mathrm{MPa}$; modifier: $4 \%$ ethanol; column: Prontosil-120 Si, $5 \mu \mathrm{m}, 250 \times 3.0 \mathrm{~mm}$; detection: UV, $254 \mathrm{~nm}, 8 \mathrm{~nm}$ bandwidth, $4 \mathrm{~nm}$ slit; $360 \mathrm{~nm}$ reference, $80 \mathrm{~nm}$ bandwidth, $5 \mathrm{~Hz}$.

a Peltier element. The detector noise of system 2 can be minimized by such a heating/cooling device, independent on the oven temperature. System 1 is equipped with a heat exchanger to cool down the mobile phase flowing from the oven to low temperature, therefore the proposed specifications are both met at lower $\left(40{ }^{\circ} \mathrm{C}\right)$ and higher temperatures $\left(100{ }^{\circ} \mathrm{C}\right)$.

\section{Composition gradient}

In pSFC, normally a constant amount of modifier is added to carbon dioxide to run analysis under isocratic conditions. During a composition gradient, the modifier content is increased and the mobile phase becomes more polar. The repeatability and the deviation between programmed and actual compositions must be tested to ensure the precision of the analysis. To visualize the gradient, UV-absorbing toluene is added to the modifier (methanol) in a concentration of about $400 \mathrm{ppm}$. The detector signal is recorded at $260 \mathrm{~nm}$. Several modifier contents are programmed in a step gradient, starting at $0 \%$. Each step should last at least 10 minutes. In this test, the chromatographic column is replaced by a capillary connection, to determine the profile created by the pump system without the additional mixing effect of a column. Four repeated gradient profiles of system 1 can be seen in figure 4 . The $2 \%$ step shows fluctuations caused by pulsation of the modifier pump at this low flow rate (zoomed area). The already modified mixing system (second mixing chamber) in place is still unable to completely smooth this inhomogeneous mixture. At the $5 \%$ level the curve is flat. The maximum deviation of the composition steps of $2 \%, 5 \%$ and $10 \%$ modifier is less than $\pm 0.2 \%$. For the higher composition steps the deviation is less than $\pm 0.5 \%$. These results fulfill the proposed specification for the composition gradient in table II.

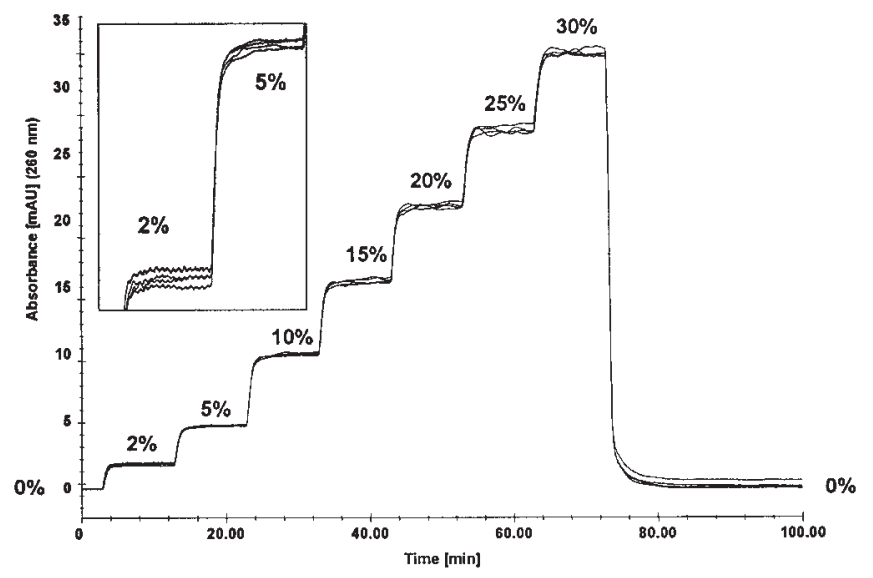

Figure 4. Profiles (repeated four times) for composition gradient testing of system 1. Conditions: flow: $2.0 \mathrm{ml} / \mathrm{min}$; outlet pressure: $20 \mathrm{MPa}$; temperature: $40{ }^{\circ} \mathrm{C}$; modifier: $0 \mathrm{~min}$ : $0 \%$ methanol + toluene (400 ppm), 2 min: $2 \%, 12 \min : 5 \%$, $22 \mathrm{~min}: 10 \%$, $32 \min : 15 \%$, $42 \min : 20 \%$; $52 \min : 25 \%$; $62 \min : 30 \%$; $72 \mathrm{~min}$ : $0 \%$; column: none; detection: UV, $260 \mathrm{~nm}$.

\section{Wavelength accuracy}

The accuracy of the wavelength setting of the UV-detector can be determined by introducing a solution of pyrene in methanol in the detector cell and scanning the spectrum. Two characteristic maxima are selected to specify the deviation: $240 \mathrm{~nm}$ and $334 \mathrm{~nm}$. These values should be recovered within a proposed range of $\pm 3 \mathrm{~nm}$.

\section{General aspects of method development}

\section{Potential of pSFC analysis during drug development}

For pSFC in general, compounds of interest must have a solubility of at least $1 \mathrm{mg} / \mathrm{ml}$ (exact amount depends on the extinction coefficient) in an organic solvent (tetrahydrofuran, acetonitrile or methanol). Aqueous samples should be avoided because of the immiscibility of water with carbon dioxide. Therefore, e.g. during development of a drug, all stress tests in aqueous solutions of drug substances are of less interest for pSFC analysis. However, stressed bulk samples which are soluble enough in organic solvents are potential candidates to try pSFC. When the LOQ is sufficient, the pSFC technique can also be used for the release analysis, and later for the comparison of the impurity profiles of different development batches used for toxicological or clinical purposes (see table I).

\section{Method development}

Standard column types in pSFC are the same as those in normal-phase HPLC (cyano, amino, diol and silica stationary 
phases). The cyano phase is a good column type to start with. The amino column can be used quite often for drug substances containing nitrogen functional groups, but without acidic functionalities.

The mobile phase is normally composed of carbon dioxide plus methanol and additives. Useful solubility information and separation behavior of a drug substance can be rapidly obtained by a preliminary multiple-gradient run from low to high mobile-phase density conditions: $10-40 \mathrm{MPa}$, 2-25\% modifier, $3 \mathrm{ml} / \mathrm{min}$, and low temperature $\left(40-60{ }^{\circ} \mathrm{C}\right)$. Additives, such as ammonium acetate or trifluoroacetic acid, can help to elute basic and acidic compounds and to prevent or reduce peak tailing.

In a pSFC testing procedure for impurity of a drug substance, the following instrumental parameters must be included in the method: column, mobile-phase composition, sample solvent, oven temperature, mobile-phase flow rate, pressure (at the column inlet and at the column outlet), injection volume, detection conditions, gradient conditions (pressure, modifier, temperature).

For a SST in a testing procedure for impurity, at least three of the following performance data must be checked before starting the analysis, with the following order of priority, if applicable: LOQ of the drug substance, repeatability of a subsequent injection series, resolution between

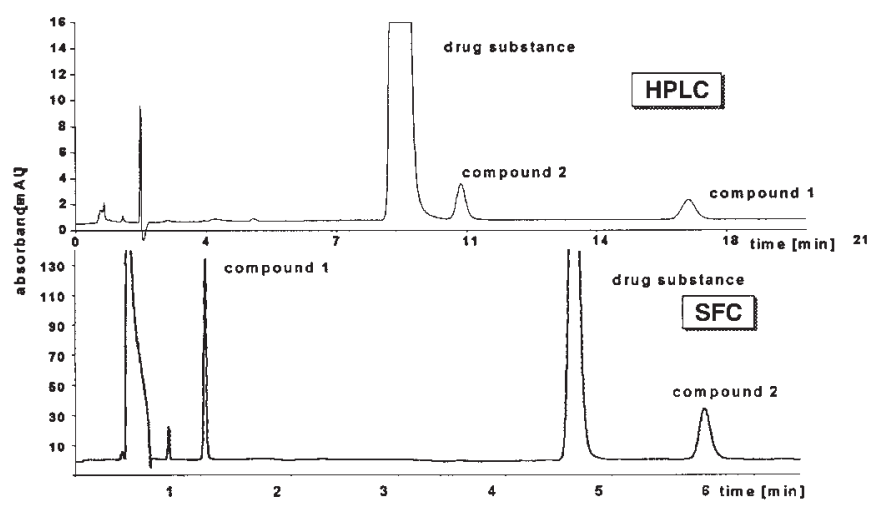

Figure 5. Comparison of RP-HPLC and PSFC methods for Novartis Pharma Drug Substance in development (NPDSD). Compound 1 and 2 are possible related substances. HPLC sample solution: of drug substance $(0.15 \mathrm{mg} / \mathrm{ml})$ spiked with compound 1,2 each $(0.0007 \mathrm{mg} / \mathrm{ml})$ in methanol + tetrahydrofuran (1:1); pSFC sample solution: of drug substance $(0.87 \mathrm{mg} / \mathrm{ml})$ spiked with compound 1,2 each $(0.10 \mathrm{mg} / \mathrm{ml})$ in tetrahydrofuran; HPLC conditions: flow: $1.0 \mathrm{ml} / \mathrm{min}$, pressure about $12 \mathrm{MPa}$, mobile phase: water+methanol+THF $(83+12+5)$, column: Nucleosil 100-5 C18 HD, $5 \mu \mathrm{m}, 125$ x $4.6 \mathrm{~mm}$, detection: UV, $220 \mathrm{~nm}$, injection: $20 \mu \mathrm{l}$; pSFC conditions: flow: $3.0 \mathrm{ml} / \mathrm{min}$, outlet pressure: $11 \mathrm{MPa}$, temperature: $35{ }^{\circ} \mathrm{C}$, modifier: $3 \%$ ethanol, column: Prontosil-120 Si, $5 \mu \mathrm{m}, 250$ × $3.0 \mathrm{~mm}$, detection: UV, $207 \mathrm{~nm}$, injection: $5 \mu \mathrm{l}$.

Table IV. Validation test parameters and their proposed specifications for assay and impurity analysis based on ICH Guideline for industry [2,3] (S/N: signal-to-noise ratio; RSD: relative standard deviation; n: number of injections).

\begin{tabular}{|c|c|}
\hline $\begin{array}{l}\leq 0.01 \% \text { dilution of } 100 \% \text { drug substance solution } \\
\leq 0.05 \% \text { dilution of } 100 \% \text { drug substance solution }\end{array}$ & $\begin{array}{l}S / N \geq 3 \\
S / N \geq 10\end{array}$ \\
\hline $\begin{array}{l}0.1-0.2 \% \\
0.2-0.5 \% \\
0.5-5.0 \% \\
>5 \%\end{array}$ & $\begin{array}{l}R S D(n \geq 6) \leq 10 \% \\
R S D \leq 20 \%(n \geq 6) \\
R S D \leq 10 \%(n \geq 6) \\
R S D \leq 5 \%(n \geq 6) \\
R S D \leq 2.5 \%(n \geq 6)\end{array}$ \\
\hline $100 \%$ & $\mathrm{RSD} \leq 1.0 \% \quad(\mathrm{n} \geq 6)$ \\
\hline $\begin{array}{l}\text { From LOQ up to } 120 \% \text { of the specified maximum } \\
\text { content of the related compound }\end{array}$ & $\begin{array}{l}\text { Correlation coefficient } \geq 0.99 \\
\text { Relative y-intercept } \leq 25 \% \\
\text { Residual standard deviation: } \\
\text { Level }<0.5 \%: \leq 10 \% \\
\text { Level } 0.5-5.0 \%: \leq 5 \% \\
\text { Level }>5 \%: \leq 2.5 \%\end{array}$ \\
\hline From 80 up to $120 \%$ of content & $\begin{array}{l}\text { Correlation coefficient } \geq 0.998 \\
\text { Relative y-intercept } \leq 2.0 \% \\
\text { Residual standard deviation } \leq 1.5 \%\end{array}$ \\
\hline $\begin{array}{l}<0.5 \% \\
0.5-5.0 \% \\
>5 \% \\
100 \% \text { (assay) }\end{array}$ & $\begin{array}{l}\text { Change } \leq 20 \% \\
\text { Change } \leq 10 \% \\
\text { Change } \leq 5 \% \\
\text { Change } \leq 2 \%\end{array}$ \\
\hline
\end{tabular}


representative peaks, tailing, and plate height. As in HPLC, quantitation is carried out by external calibration.

To demonstrate the validation of an analytical assay and an impurity method using pSFC, an example of a Novartis Pharma drug substance (NPDSD) is described. This drug substance mainly shows two possible related substances beside the drug substance. The chromatograms using RPHPLC and pSFC are compared in figure 5. During pSFC method development, the following parameters were tested to finalize the testing procedure for assay and impurity:

- Columns: silica, aminopropyl, and cyano phases;

- Modifiers: methanol, ethanol, methanol plus ammonium acetate, ethanol plus ammonium acetate;

- Outlet pressure: 11-20 MPa;

- Temperatures: $35-80{ }^{\circ} \mathrm{C}$.

The best resolution between the drug substance and compound 2 of NPDSD was achieved using the conditions shown in figure 5. In contrast with the RP-HPLC result, in pSFC (normal-phase separation mechanism), compound 1 is eluted before the drug substance (Fig. 5), while compound 2 is eluted in the same order as in RP-HPLC.

\section{Validation}

The validation parameters and their proposed specifications for chromatographic methods based on ICH Guidelines for industry $[2,3]$ are summarized in table IV. According to the different concentration ranges in question, the specifications of assay and impurity parameters are different. In the first case, the amount of the drug substance is quantified; in the second case, related substances at low level are quantified. NPDSD was used to demonstrate the validation of the analysis of a drug substance for LOD, LOQ, linearity, and repeatability. Solutions with concentrations in the range between $100 \%$ and $0.005 \%$ of NPDSD were injected. Each injection was repeated six times, starting with the lowest concentration.

\section{$\angle O D$ and $L O Q$}

According to the ICH Guidelines for industry, signal-tonoise ratios $(\mathrm{S} / \mathrm{N})$ of $3: 1$ and 10:1 are generally considered as acceptable for estimating LOD and LOQ respectively.

For LOD determination, the S/N of the $0.005 \%$ solution can be calculated as demonstrated in figure 6: the baseline noise is determined in a time range, which corresponds to ten times the peak-width-at-half-height before and after the peak. This noise level is equal to the one determined in the blank run in the same time range (lower chromatogram in figure 6). $\mathrm{S} / \mathrm{N}$ is calculated as follows: the signal height is divided by this noise level, in this example the result is 2.6. The average of the six injections is 3 , which meets the proposed requirements for LOD according to table IV.

For LOQ determination, the $0.05 \%$ solution gives a peak with an average $\mathrm{S} / \mathrm{N}$ of 20 , which meets the proposed LOQ

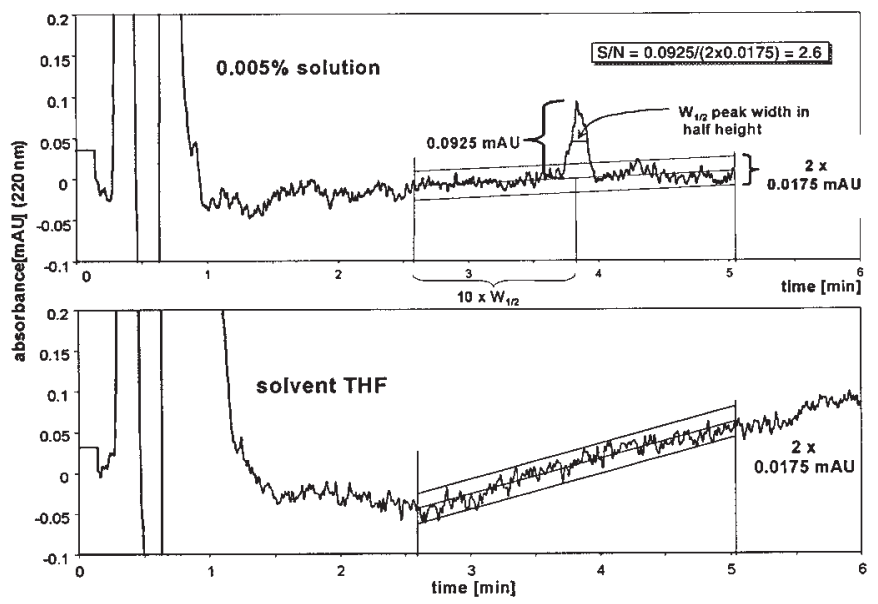

Figure 6. Determination and calculation of signal-to-noise ratio for the LOD of Novartis Pharma Drug Substance in development (NPDSD) using pSFC system 2. pSFC conditions: flow: $2.0 \mathrm{ml} / \mathrm{min}$; outlet pressure: $11 \mathrm{MPa}$; temperature: $40{ }^{\circ} \mathrm{C}$; modifier: $4 \%$ ethanol; column: Prontosil-120 Si, $5 \mu \mathrm{m}, 250 \times 2.0 \mathrm{~mm}$; injection: $10 \mu \mathrm{l}$; detection: UV, $220 \mathrm{~nm}, 8 \mathrm{~nm}$ bandwidth; $360 \mathrm{~nm}$ reference, $80 \mathrm{~nm}$ bandwidth.

requirement of $\mathrm{S} / \mathrm{N} \geq 10$ according to table IV. A summary of $\mathrm{S} / \mathrm{N}$ for the concentration range of $0.005 \%$ to $0.5 \%$ is given in table $\mathrm{V}$.

\section{Precision: repeatability}

According to ICH Guidelines for industry, a minimum of nine determinations covering the specified range for the procedure (e.g. three concentrations with three replicates each) should be performed. The precision of the peak area of NPDSD is calculated by the RSD values for six repeated injections for each of the five concentrations shown in figure 7 . For the $0.05 \%$ solution, the precision is about $1.5 \%$, which is quite below the proposed requirements of $10 \%$ for LOQ (table IV).

\section{Precision: intermediate precision}

According to the ICH Guidelines for industry, typical variations have to be evaluated including different days, analysts, and equipment. In the case of the NPDSD, the method transfer between the two pSFC systems is important. As shown in figure 8 , the selectivity is sufficient in both systems. Although the same nominal conditions are used (chromatography, column, and sample), the retention times are shifted. Because of the difference in flow rates, which was already demonstrated in figures 1 and 2, this fact must kept in mind when setting the SST parameters in the testing procedure.

\section{Linearity}

According to ICH Guidelines for industry, the linearity must be checked from the reporting level of an impurity up to 


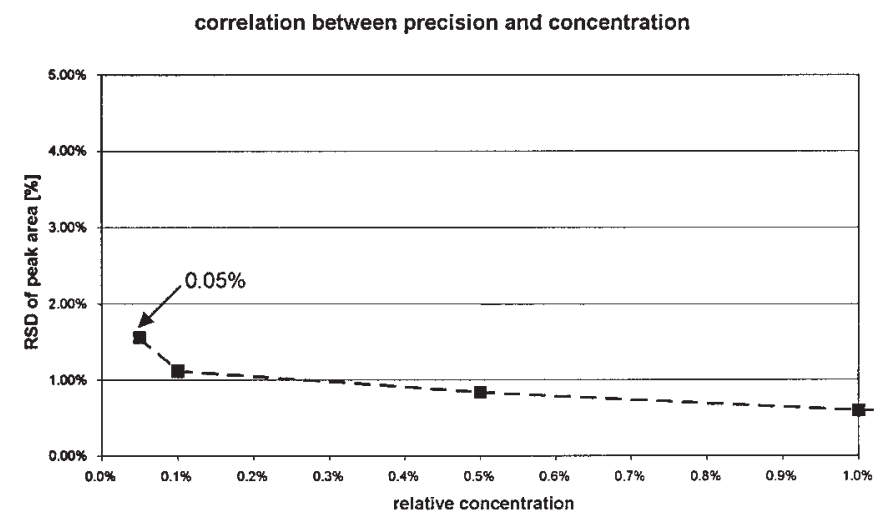

Figure 7. RSD of six repeated injections versus each concentration of Novartis Pharma Drug Substance in development (NPDSD) (for pSFC conditions, see figure 6).

$120 \%$ of the specified level. In the range of 0.005 to $1 \%$ (five concentration levels), the correlation coefficient is 0.99996, which fulfills the proposed specification for impurity $(r \geq 0.99)$ in table IV. The correlation coefficient in the whole range from $0.005 \%$ up to $100 \%$ of the drug substance in development is $r=0.99975$, which fulfills the proposed requirement in table IV for assay $(r \geq 0.998)$.

\section{Outlook}

The present work demonstrates that the pSFC technique can fulfill the requirements of ICH and cGMP environments in general and is therefore a suitable tool for drug substance and drug product analysis in the pharmaceutical industry. The requirements concerning reliability, precision, and sensitivity can be met by pSFC as well as by HPLC. As an orthogonal separation technique, pSFC can also be used to ensure the results of new developed or routine RP-HPLC. However, further pSFC instrumental improvements are required to achieve quantitation on the same low level as

Table V. Summary of relative concentration of Novartis Pharma Drug Substance in development (NPDSD) and its average $S / N(n=6)$. Conditions: as in figure 6 .

\begin{tabular}{cc}
\hline Relative concentration [\%] & Average $S / N(n=6)$ \\
\hline 0.005 & 3 \\
0.05 & 20 \\
0.1 & 44 \\
0.5 & 203 \\
\hline
\end{tabular}

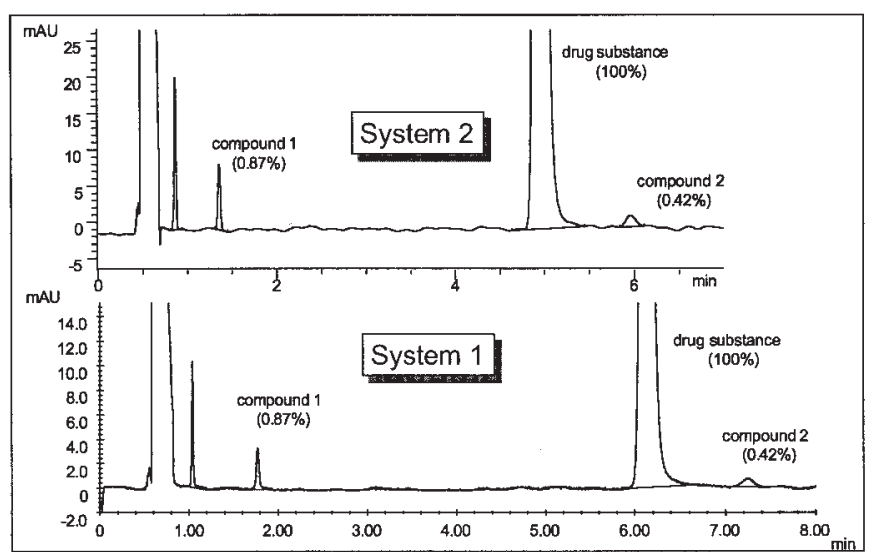

Figure 8. Method for Novartis Pharma Drug Substance in development (NPDSD) using different pSFC systems. Sample solution in tetrahydrofuran: drug substance: $0.96 \mathrm{mg} / \mathrm{ml}(100 \%)$ spiked with compound 1: $8.29 \mu \mathrm{g} / \mathrm{ml} \quad(0.87 \%)$, compound 2: $4.06 \mu \mathrm{g} / \mathrm{ml}(0.42 \%)$; pSFC conditions: flow: $3.0 \mathrm{ml} / \mathrm{min}$, outlet pressure: $11 \mathrm{MPa}$, temperature: $35{ }^{\circ} \mathrm{C}$, modifier: $3 \%$ ethanol; column: Prontosil-120 Si, $5 \mu \mathrm{m}, 250 \times 3.0 \mathrm{~mm}$, detection: UV, $207 \mathrm{~nm}$ (system 1), UV, $207 \mathrm{~nm}, 8 \mathrm{~nm}$ bandwidth, $360 \mathrm{~nm}$ reference, $80 \mathrm{~nm}$ bandwidth (system 2), injection: $5 \mu \mathrm{l}$.

with HPLC. Concerning the UV-detector noise amplitude, the influences of temperature and mixing quality of the highly compressible mobile-phase are mostly ignored. Special attention must also be given to possible differences in flow rates of the compressible fluid and/or regulation of the back-pressure using different pSFC instrumentation, which can have a great impact on method transfer. Realistic specifications in an appropriate instrumental SOP for pSFC can help to ensure smooth method transfers between different pSFC instruments.

\section{References}

1. Vessman, J. In Encyclopedia of Analytical Science: Pharmaceutical Analysis; Townshend, A. Ed.; Academic Press Ltd: London, UK, 1995; pp 3798-3808.

2. Guideline for Industry: Text on Validation of Analytical Procedures, ICH Q2A, March 1995.

3. Guideline for Industry: Validation of Analytical Procedures, Methodology, ICH Q2B, November 1996.

4. Guideline for Industry: Impurities in New Drug Substances, ICH Q3A, January 1996.

5. Guideline for Industry: Impurities in Dosage Forms, ICH Q3B, November 1996.

6. FDA Federal Register, 62, 227, 62890-62910.

7. Lacroix, P. Encyclopedia of Analytical Science: Pharmaceutical Analysis; Academic Press Ltd: London, UK, 1995, pp 3808-3813.

8. Schier, J. LC GC 1995, 13, 474-479. 
9. Burgees, C.; McDowall, R. D. LC GC 1997, 15, 130-135.

10. Anton, K.; Bach, M.; Geiser, A. J. Chromatogr. 1991, 553, 7179.

11. Scalia, S.; Games, D. E. J. Pharma. Sci. 1993, 82(1), 44-47.

12. Vérillon, F.; Heems, D.; Pichon, B.; Coleman, K.; Robert, J. C. Am. Lab. 1992, 25, 45-53.

13. Kornfeld, R. Am. Lab. 1992, 24, 25-32.

14. Anton, K. Encyclopedia of Analytical Science: Instrumentation; Townshend, A. Ed.; Academic Press Ltd.: London, UK, 1995; pp 4856-4862.
15. Berger, T. Chemical Basis for the Instrumentation used in Packed Column Supercritical Fluid Chromatography, Supercritical Fluid Chromatography with Packed Columns, techniques and Applications; Anton, K.; Berger, C. Eds.; Chromatographic Science Series, Vol. 75, 1998; pp 19-58.

16. V.6.20.101 Chromatographie mit Überkritischen Phasen, $\mathrm{Ph}$. Helv. VII - Supplement. Eidgenössisches Department des Inneren, 1994, Bern, Switzerland.

17. Reference Manual HP1100 Series Diode Array Detector, Hewlett-Packard G1315-90001, 1996, 230. 